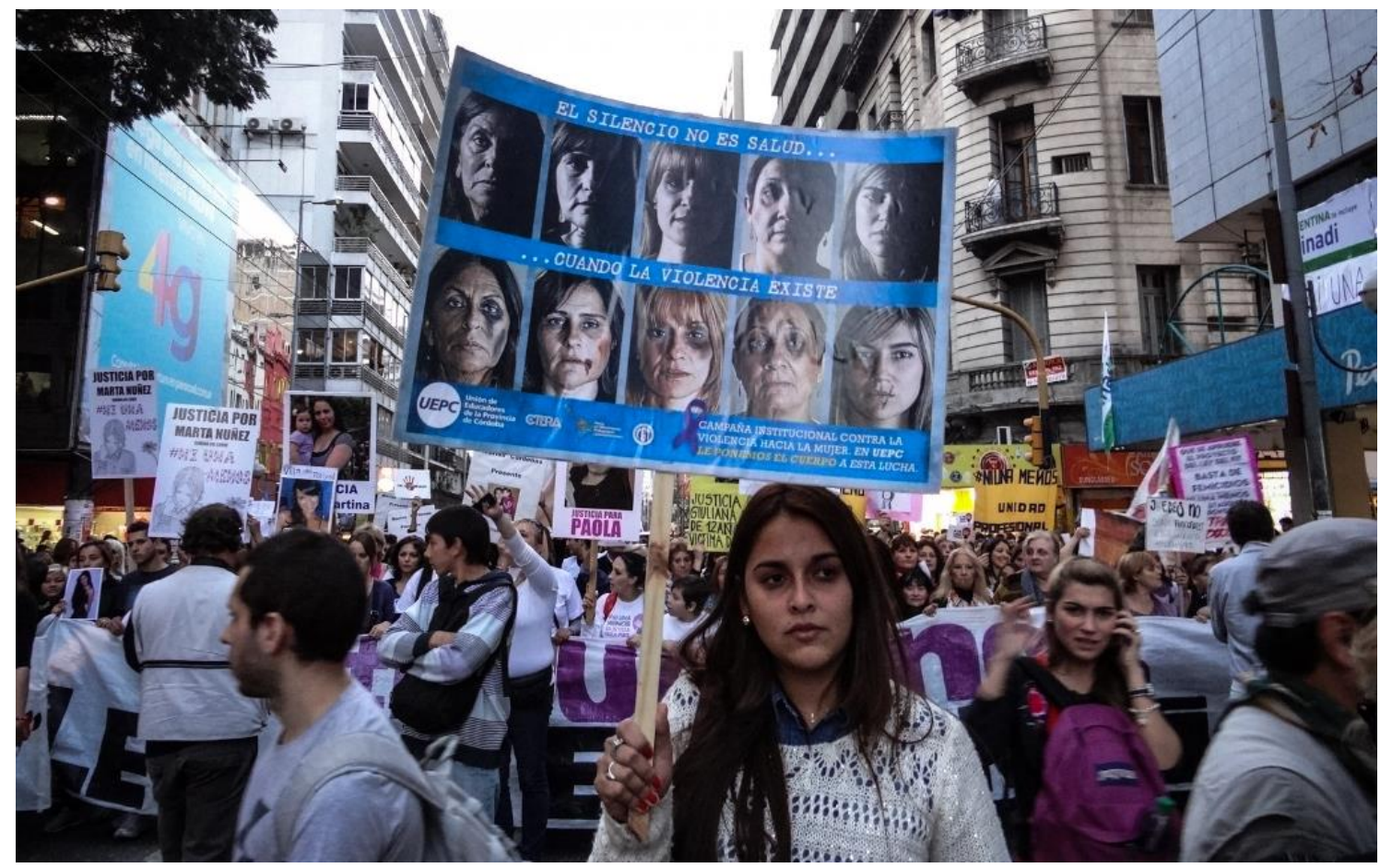

FOTOS: Irina Morán - Revista Alfilo - Periodista Feminista. Militante de Ni Una Menos Córdoba y Mujeres por un parto Respetado 


\title{
AS TIC's NA EDUCAÇÃO INFANTIL: CONTRIBUIÇÕES DO FACEBOOK PARA A APRENDIZAGEM E PARA A INTEGRAÇÃO FAMÍLIA E ESCOLA
}

\author{
Luciano Andreatta da Costa ${ }^{1}$ \\ Silvana Castilhos Steyer ${ }^{2}$ \\ Maria Altina Silva Ramos ${ }^{3}$
}

\begin{abstract}
Resumo: A revolução tecnológica a cada dia aumenta e transforma de forma significativa diversos setores da sociedade: econômicos, culturais, sociais e educacionais. Os meios tecnológicos, através da informática, se fazem presentes na sociedade moderna. As crianças pequenas não estão alheias a esta gama de informações que são disponibilizadas pelas Tecnologias de Informação e Comunicação (TIC's). As tecnologias promovem mudanças expressivas em toda a sociedade, e, consequentemente na educação, na qual devem estar presentes, pois instituem novas formas de comunicação e estimulam as já existentes. Neste contexto, este artigo, elaborado a partir de uma pesquisa de mestrado, visa trazer uma contribuição para o campo educacional e analisar o interesse educativo do uso das TIC's na Educação Infantil. Com isso busca-se lançar um olhar sobre as contribuições do grupo "Turminha Legal" no Facebook, para ligar família-escola em torno dos conteúdos escolares, a partir de uma abordagem qualitativa, desenvolvida de forma indutiva e sistemática no contexto de um estudo de caso. Os resultados obtidos pelo presente estudo corroboram a importância da inserção das tecnologias no ambiente escolar, e, consequentemente na educação infantil.
\end{abstract}

Palavras-chave: TIC's na Educação; Facebook; Educação infantil; Interação família-escola; Ensino e aprendizagem

\section{ICT IN EARLY CHILDHOOD EDUCATION: FACEBOOK'S CONTRIBUTIONS TO LEARNING AND TO INTEGRATE FAMILY AND SCHOOL}

\begin{abstract}
The technological revolution every day increases and transforms in a significant way diverse sectors of the society: economic, cultural, social and educational. Technological means, through computer science, are present in modern society. Young children are not unaware of this range of information that is available through Information and Communication Technologies (ICTs). Technologies promote significant changes throughout society, and consequently in education, in which they must be present, for they institute new forms of communication and stimulate those already existing. In this context, this paper, based on a master's research, aims to bring a contribution to the educational field and to analyze the educational interest of the use of ICT in Early Childhood Education. With this, it is aimed to take a look at the contributions of the group "Turminha Legal" on Facebook, to link familyschool around the school contents, from a qualitative approach, developed in an inductive and systematic way in the context of a study of case. The results obtained by the present study corroborate the importance of the insertion of the technologies in the school environment, and consequently in the infantile education.
\end{abstract}

\footnotetext{
${ }^{1}$ Possui graduação em Engenharia Civil e Licenciatura em Matemática, pela Universidade Federal do Rio Grande do Sul - UFRGS, especialização em Edificações pela PUCRS, mestrado e doutorado em Engenharia Civil pela UFRGS, no tema da Educação em Engenharia, tendo sido a tese premiada pelo PAPED - Programa de Apoio à Pesquisa em EAD da CAPES. É Professor Adjunto da Universidade Estadual do Rio Grande do Sul - UERGS; Faz parte do corpo docente dos cursos de Engenharia de Energia e Engenharia de Bioprocessos e Biotecnologia; Professor colaborador do Programa de PósGraduação em Educação em Ciências: Química da Vida e Saúde - PPGQVS da Universidade Federal do Rio Grande do Sul - UFRGS.

2 Mestre em Educação em Ciências da Educação Especialidade em Tecnologia Educativa pela Universidade do Moinho.

${ }^{3}$ Professora auxiliar no Departamento de Estudos Curriculares e Tecnologia Educativa da Universidade do Minho. Investigadora associada ao Centro de Investigação em Educação. Licenciada em Línguas e Literaturas Modernas pela Faculdade de Letras da Universidade do Porto, Mestre em Estudos Ibéricos: multimédia e didática das línguas pela Université de Toulouse le-Mirail, Doutora em Estudos da Criança, especialidade Tecnologia Educativa. Atua nas linhas de TIC e currículo, TIC em processos de ensino/aprendizagem, TIC e Ensino de Línguas, TIC e Metodologia de Investigação (grounded theory, NVivo), TIC e formação de professores.

Momento: diálogos em educação, E-ISSN 2316-3100, v. 28, n. 3, p. 390-409, set./dez, 2018.
} 
Keywords: ICT in Education; Facebook; Childhood education; Family-school interaction; teaching and learning.

\section{INTRODUÇÃo}

A revolução tecnológica digital que presenciamos atinge todos os segmentos da sociedade, exercendo grandes transformações na vida das pessoas. Neste contexto, os indivíduos trabalham, comunicam-se, ensinam e aprendem de formas diferentes. Ressalta-se que a escola não está alheia a este processo. Esse novo cenário tecnológico impõe à escola, a necessidade de que todos aprendam a organizá-la para inovação, proporcionando um espaço para a criação e reflexão.

Para Silva (2012), a escola deve ser inclusiva, sob o ponto de vista da interface digital, sendo uma exigência para a ocupação do novo espaço de comunicação cultural, que proporciona ao professor superar a pedagogia tradicional, possibilitando que seu aluno desenhe suas trajetórias.

Este artigo apresenta reflexões acerca deste pensamento, procurando compreender a aprendizagem na Educação Infantil, e, lançando olhar para as ferramentas de informação e comunicação, como alternativa pedagógica possível de ser empregada no quotidiano escolar. Pretende-se refletir acerca da utilização de atividades e jogos interativos com o auxílio do computador, como recurso didático na construção da aprendizagem. A boa atuação da criança nos anos iniciais do ensino fundamental e, portanto, sua permanência na escola está relacionada à realização de um bom trabalho na educação infantil, primeira etapa da vida escolar. Existe a certeza da necessidade de se iniciar desde bem cedo a estimular as crianças da educação infantil o pensamento lógico, abstrato, por meio de conceitos matemáticos, com um ambiente lúdico e descontraído que ambientes tecnologicamente enriquecidos podem proporcionar: “[...] a criança vai construir seu conhecimento matemático por meio de sucessivas reorganizações ao longo da sua vida.” (RCN, 2008, p. 214).

A tecnologia faz parte de nossas vidas, colocou-nos a viver num novo mundo, de tal modo que a expressão sociedade da informação passou a ser usada para identificar esse novo tempo. Assim, temos que refletir acerca das contribuições que as TIC's podem proporcionar à organização escolar e curricular. Elas proporcionam um espaço de profunda renovação da escola e todos os que fazem parte do processo 
educativo.

Esta investigação foi orientada por uma abordagem qualitativa, centrada no estudo de caso, na busca de significados para os sujeitos em questão. Visando atender aos objetivos dessa pesquisa foram empregados como instrumentos de coleta de dados, entrevista, observações, diário de campo e projeto de intervenção. A coleta desses materiais foi efetivada através dos sujeitos participantes dessa investigação que são vinte alunos e seus familiares da Educação Infantil de uma escola estadual pública do município de São Francisco de Paula.

\section{CONTEXTUALIZAÇÃO E JUSTIFICATIVA DO ESTUDO}

Desde o surgimento da humanidade o ser humano possui necessidade de se comunicar. Com o advento das tecnologias comunicacionais, especialmente com a Internet destaca-se mudanças significativas na forma como interagimos e nos comunicamos na sociedade. E, a educação vem a cada dia usufruindo dos artefatos dos computadores em rede para buscar formas de aprendizagem coerentes com a sociedade atual. As redes sociais representam grande tendência em compartilhar informações e conhecimentos, pois neste ambiente as pessoas se relacionam com outros indivíduos e fazem parte dos grupos que possuem maior afinidade.

Nos dias de hoje, o Facebook é a rede social mais utilizada em todo o mundo, principalmente no que se refere à interação social, percebida através dos comentários nas publicações e pela participação em grupos abertos, fechados ou secretos que tenham o mesmo assunto para discussões e compartilhamento. A facilidade de conversação, a diminuição das relações hierárquicas de poder entre professor e alunos e características comunicacionais e de interatividade, com a possibilidade de pensar numa aprendizagem com um currículo mais flexível, extrapolar o tempo e espaço formal, bem como oferecer novas formas de tratar o conhecimento no âmbito escolar são algumas vantagens do uso do Facebook na educação.

\subsection{Justificativa sócio-educacional}

A educação vem sendo desafiada a cada dia. Os modos de pensar e agir muda com as transformações das culturas e das gerações. A escola de hoje não pode ficar indiferente à sociedade da informação e do conhecimento. A escola precisa ficar atenta Momento: diálogos em educação, E-ISSN 2316-3100, v. 28, n. 3, p. 390-409, set./dez, 2018. 
a estas mudanças no sentido de dialogar com a realidade dos sujeitos e refletir com o sistema à necessidade de se apropriar das ferramentas de comunicação atuais, como mediadoras do processo de ensino e aprendizagem.

\subsection{Justificativa científica}

"A tecnologia mune o professor de novas ferramentas e convida-o a uma mudança de práticas, incentiva-o à inovação, no sentido de dinamizar um ensino mais motivador, dinâmico, interativo e participativo.” (Ferreira, 2009, p. 34). Neste sentido, busca-se o aprofundamento no conhecimento atual sobre o objeto desta pesquisa.

\section{AS TECNOLOGIAS DE INFORMAÇÃO E COMUNICAÇÃO NA EDUCAÇÃO}

O advento das TIC's traz vastas possibilidades para se refletir acerca da inclusão das mesmas na sociedade, e, consequentemente na educação. O ser humano foi no decorrer dos tempos buscando diferentes formas para se comunicar. O desenvolvimento das TIC's está ligado a uma evolução que teve início através dos correios, passando ao rádio e televisão, vídeos, computadores e chegando até as mais modernas transmissões de conferências via satélite, tendendo avançar e se transformar frequentemente. Desta maneira, antes mesmo do uso da Internet, as pessoas já utilizavam outras tecnologias de comunicação para interagir ou estudar. Na esfera educacional a instituição tecnológica e a concentração das mídias oferecem às pessoas a reciprocidade de informações e a aprendizagem colaborativa. "O uso da tecnologia na educação permite a extrapolação do universo possível de interações dos espaços tradicionais de aprendizagem". (RODRIGUES, TAROUCO \& KLERING, 2014, p. 23). O que demanda à escola, em caráter primordial de que todos que tenham interesse aprendam a pensá-la e organizá-la perante o novo design tecnológico, favorecendo um ambiente para a reflexão e as atividades criadoras.

A construção de novas formas de aprender e de formar, mais de acordo com o funcionamento e as necessidades educativas da sociedade de informação, parece assentar hoje em três aspetos fundamentais: i) a constante evolução das TIC's; ii) a necessidade de formação permanente; iii) a emergência da atividade coletiva como modelo potencialmente válido de aprendizagem". (MEIRINHOS \& OSÓRIO, 2014, Momento: diálogos em educação, E-ISSN 2316-3100, v. 28, n. 3, p. 390-409, set./dez, 2018. 
p. 8). Neste novo cenário, a escola, como espaço de criação lança aos sujeitos que integra este processo coletivo de aprendizagem o comprometimento com a mudança levando sempre em consideração o aprendizado como um dos desafios mais importantes. Sendo necessário refletir que a tecnologia por si só não garante à aprendizagem, porém o gestor precisa ser o mediador para que se tenha uma escola preparada para receber e estimular o acesso às TIC's e dispor todo o seu potencial em favor da aprendizagem. A ideia é transpor a visão de uso da tecnologia para a da realização de atividades adicionais e posicioná-la como um recurso capaz de colocar o aluno em caminhos tais que o conhecimento construído seja depois compartilhado, e é nesse compartilhar que se vivencia a aprendizagem colaborativa. (RODRIGUES, TAROUCO \& KLERING, 2014, p. 24).

É neste contexto que Meirinhos e Osório (2014) enfatizam que as TIC's promovem o trabalho colaborativo, porém, a capacitação de formadores e formandos é fundamental. Mas não somente a capacitação para o domínio das TIC's e sim na criação de competências para o desenvolvimento profissional. Segundo Silva (2001) se a escola não reorganizar o seu método, em relação à inserção das TIC's, e não possuir gestores capazes, bem como professores não existe tecnologia que dê conta dos problemas. Pois, as tecnologias podem alterar a forma como as competências são realizadas, mas não podem fazer um "mau" professor se transformar em um "bom" professor. As repercussões em relação à metodologia prendem-se com as possibilidades de se criarem metodologias singulares e variadas adaptadas ao perfil de cada aluno e aos contextos de aprendizagem. Trata-se de aplicar uma pedagogia diferenciada. As TIC's permitem valorizar o método, o processo, o itinerário, o como, dando aos professores a possibilidade de ensinarem de "outro modo", permitindo pensar num paradigma metodológico que rompa com o modelo de pedagogia uniformizante. (BENTO, 2001, p. 848). Possibilitar condições para que os educadores agreguem as TIC's à prática pedagógica, prevê uma formação de qualidade, na qual o professor estará apto a fazer uso criativo, reflexivo e inovador das mesmas e desenvolver com seus alunos um trabalho colaborativo. A consolidação do processo de integração das TIC's às práticas desenvolvidas em sala de aula, bem como ao currículo, favorece mudanças significativas, como a flexibilidade curricular e a combinação de atividades à distância e presenciais.

É neste sentido que se almeja uma gestão escolar de qualidade, a qual estimula a criação de ambientes para aprendizagem, onde a socialização, a realidade local e as Momento: diálogos em educação, E-ISSN 2316-3100, v. 28, n. 3, p. 390-409, set./dez, 2018. 
interações possibilitem a construção expressiva de novos conhecimentos. Logo, gerir a tecnologia na escola demanda que o gestor compreenda as transformações que ocorrem na sociedade, bem como as consequências dessas transformações para o crescimento humano. Isso solicita ações em relação há mudanças estruturais que vão além da instalação do computador e da Internet na escola. "Exige a compreensão de que as TIC são meios de acesso a educação, ao trabalho, ao exercício da cidadania, ao lazer, ao mundo. [...] numa visão redimensionada de gestão democrática, participativa, consciente e responsável”. (RODRIGUES, TAROUCO \& KLERING, 2014, p. 30).

O trabalho pedagógico é ponto central da escola, nesse novo tempo, é primordial que o gestor escolar potencialize o fazer pedagógico gerindo com eficiência as novas tecnologias, de modo a proporcionar a inserção das mudanças na gestão, na prática do professor e na concepção pedagógica da escola. Pois, apesar de mudanças culturais e sociais significativas, as escolas do Brasil necessitam ainda de mais engajamento no uso das TIC's em sala de aula.

\subsection{Perspectiva histórica}

Segundo Almeida (2008), a inserção da informática na educação no Brasil e em Portugal aconteceu no final da década de 1970 e início da década de 1980, com a instalação dos primeiros computadores nas escolas. Junto com os computadores chegaram as impressoras, drivers externos, scanners e as câmeras digitais. Todos esses equipamentos foram identificados como tecnologia de informação (TI). Este processo teve como estratégia capacitar profissionais para competência científico-tecnológica para atuar nos setores produtivos.

Em Portugal, foi criado o Projeto Minerva (Meios Informáticos no Ensino: Racionalização, Valorização e Atualização), que visava “inclusão do ensino das tecnologias de informação nos planos curriculares; o uso das tecnologias de informação como meios auxiliares do ensino das outras disciplinas escolares, e a formação de orientadores, formadores e professores". (PONTE apud FERREIRA, 2009. p. 34).

Conforme os estudos de Ferreira (2009), o Ministério da Educação de Portugal financiava o Projeto Minerva e as universidades e escolas superiores davam o suporte técnico para sua execução. Sendo assim, o Projeto possibilitou que milhares de alunos e professores usufruíssem dos computadores como ferramenta de aprendizagem no desenvolvimento de suas atividades, permitindo a exploração de alguns recursos Momento: diálogos em educação, E-ISSN 2316-3100, v. 28, n. 3, p. 390-409, set./dez, 2018. 
informáticos como "o processador de texto, a folha de cálculo, as bases de dados, o desenho assistido por computador, a edição eletrônica e softwares educativos". (Ferreira, 2009. p. 34)

Também visava à formação de professores em nível das competências técnicopedagógicas, para que pudessem fazer uso das tecnologias de informação no processo de ensino e aprendizagem. O mesmo autor, citado acima, frisa que, com o Projeto Minerva, iniciou-se uma discussão sobre a importância da utilização e da divulgação das tecnologias na educação junto a uma parte significativa da população. Além do mais, abriu portas para outros programas, como o Programa Internet na Escola (1997), coordenado pelo Ministério da Ciência e Tecnologia, que tinha o objetivo de equipar todas as escolas com um computador multimídia conectado à internet na biblioteca, visando a uma melhoria nas condições de igualdade e acessibilidade à informática de toda a comunidade.

No Brasil, a inserção dos programas de informática na educação também aconteceu na década de 1970, principalmente em universidades, por meio de pesquisas e experimentos. Foi criado o EDUCOM (Educação com Computador), a partir da aceitação da informática como ferramenta de reafirmação da sociedade pós-industrial e de estudos a respeito da sua utilização na educação, para a informatização da sociedade brasileira. Nesse programa, a Secretaria de Especialização de Informática - SEI solicitou aos estabelecimentos de ensino superior a elaboração de projetos de implantação de centros-piloto para desenvolver estudos sobre o uso do computador como recurso de ensino-aprendizagem, principalmente no $2^{\circ}$ grau, criando grupos com equipes multidisciplinares e professores do magistério público, para que estes criassem sistemas interativos, softwares de apoio educacional, capacitassem recursos humanos para as atividades e avaliassem seguidamente a utilização do computador em educação nos aspectos lógicos, psicopedagógicos e socioculturais.

Os centros-piloto teriam de ser capazes de auxiliar nas decisões políticas para área e servir de referência para difusão na formação de recursos humanos. Também tinham como propósito verificar a ocorrência de possíveis mudanças na estrutura dos sistemas de ensino público, buscando alternativas adequadas à realidade social, política, econômica e cultural. Em 1984, os centros-piloto ou subprojetos EDUCOM foram instalados nas universidades federais de Pernambuco, Minas Gerais, Rio de Janeiro, Rio Grande do Sul e estadual de Campinas, em São Paulo - os quais produziram resultados importantes para o desenvolvimento de estratégias governamentais e para a utilização Momento: diálogos em educação, E-ISSN 2316-3100, v. 28, n. 3, p. 390-409, set./dez, 2018. 
da informática na educação.

Em consequência, foram criados Comitês de Assessoramento de Informática na Educação, destacando ações básicas de consolidação de uma cultura nacional de informática educacional, tais como: Projeto FORMAR (1987, 1989 e 1992); Projeto CIEd - que implantou Centros de Informática na Educação junto às secretarias estaduais de educação; Jornadas de Trabalho com subsídios para políticas e concursos de softwares educativos (1987-1989). Todos estes projetos tinham como objetivo incentivar novos talentos, a produção descentralizada e a melhoria da qualidade.

Foi criado, também, o PRONINFE (1989) - Projeto Nacional de Informática Educativa, com o intuito de capacitar professores, técnicos e pesquisadores de forma contínua e permanente para o domínio da informática educativa. Segundo Oliveira (2014), somente em 1997, foram instalados programas de informática nas escolas públicas brasileiras, por meio do Programa Nacional de Informática na Educação (PROINFO), vinculado à Secretaria de Educação a Distância/SEED. O objetivo principal deste Programa, conforme Valente (1999) apud Oliveira (2014), é estabelecer relações com a escola pública, buscando a inserção da informática na educação básica, através da interação de técnicos, pesquisadores e governo. O autor ainda arqgumenta que, no Brasil, sempre existiu a preocupação de usar o computador não somente para a transmissão de informações e conhecimento, como ferramenta para informatizar os processos de ensino já existentes, mas, sim, como instrumento de interação.

Neste sentido, reforça-se a ideia de que o uso do computador não é somente para mera transferência de informações, pode ser usado pedagogicamente nos processos de ensino e aprendizagem. Pesce (2011) nos lembra que, além do computador, a história da educação, no Brasil, se caracterizou pela utilização de material impresso e do rádio como aliados nos cursos oferecidos na Educação a Distância, na década de 1940.

Sendo assim, o que podemos perceber é que a educação sempre esteve mediada por algum meio de comunicação como suporte às ações do educador em sua interação com os estudantes. A própria sala de aula pode ser considerada uma "tecnologia", e todos os recursos utilizados pelo professor como ferramentas pedagógicas: o giz, o livro, a caneta, o quadro-negro. "Pedagogia e tecnologia sempre foram elementos fundamentais e inseparáveis da educação". (Belloni, 2009, p. 53-54).

Leite \& Ribeiro (2012) destacam a expressão criada com a chegada da Internet: Tecnologia de Informação e Comunicação - permite criar, capturar, interpretar, armazenar, receber e transmitir informações. Para os autores, a inserção dessas Momento: diálogos em educação, E-ISSN 2316-3100, v. 28, n. 3, p. 390-409, set./dez, 2018. 
tecnologias na educação representam melhorias no processo de ensino-aprendizagem. Conforme essas tecnologias são usadas, podem trazer resultados positivos ou negativos. Para que sejam usadas de forma positiva, são necessários alguns fatores: o domínio do professor sobre as tecnologias e sua utilização na prática; boa estrutura física e material por parte da escola; investimento dos governos em capacitação para a formação de professores frente aos avanços tecnológicos; manutenção da motivação do professor para aprender e inovar em sua prática pedagógica; integração nos currículos escolares acerca da utilização das novas tecnologias aos seus conteúdos. (LEITE \& RIBEIRO, 2012, p. 175).

Assim, percebemos que, a cada dia, a tecnologia passa a fazer mais parte de nossas vidas. Com as escolas cada vez mais conectadas à Internet, colocou-nos a viver num mundo diferente e diversificado, de tal modo que a expressão sociedade da informação passou a ter um uso frequente para identificar essa nova configuração. Assim, temos que refletir sobre as contribuições que as TIC's podem proporcionar à nova organização escolar e curricular que se apresenta. As Tecnologias de Informação e Comunicação proporcionam um espaço de profunda mudança da escola, exigindo dos educadores uma grande capacidade de adaptação e de desafio: transformar o modelo escolar que privilegia a lógica da instrução e da transmissão de informação para um modelo escolar baseado na construção colaborativa de saberes. Ou seja, como salienta Moran (2007), o professor precisa aprender a manipular com as tecnologias mais modernas, não se acomodando, porque, a todo instante, surgem novas tecnologias para facilitar o trabalho pedagógico.

A utilização dos computadores por parte dos educadores, em seu ambiente de aprendizagem, possibilita que os alunos interajam com outros indivíduos, pesquisando sobre diferentes assuntos e fazendo uso de ferramentas tecnológicas no ensino, o que torna este processo mais dinâmico e atrativo. Valente (1999) afirma que as políticas de implantação da informática, na escola pública brasileira, têm sido direcionadas com vistas na mudança pedagógica:

As mudanças pedagógicas que podem ser observadas são, atualmente, propiciadas pelo uso da rede Internet. Por intermédio da Internet, os alunos têm a chance de acessar e explorar diferentes bases de dados e construir páginas para registrar os resultados de projetos ou atividades desenvolvidas. (VALENTE, 1999, p. 04). A mudança pedagógica que todos querem é transformar uma educação voltada para a transmissão de informação e instrução para a elaboração de espaços de aprendizagem, Momento: diálogos em educação, E-ISSN 2316-3100, v. 28, n. 3, p. 390-409, set./dez, 2018. 
nos quais os estudantes desenvolvem suas atividades e constroem seu conhecimento. Segundo Belloni (2009), as facilidades oferecidas pelas TIC's trazem mudanças significativas nas possibilidades de interação, colocando à disposição dos sistemas, dos alunos e professores técnicas rápidas, seguras e eficientes. Possibilita o usuário a interagir por meio da máquina (professor/aluno; aluno/aluno; professor/família e até mesmo aluno/família). As técnicas de interação criadas pelas redes telemáticas (e-mail, facebook, webs, sites.) são de grande valia, permitem combinar a flexibilidade da interação humana com a independência no tempo e no espaço.

Nesse sentido, é necessário refletir acerca deste novo formato que surge para se comunicar novos espaços possíveis para a interação acontecer. Portanto, cabe a todos os envolvidos, neste processo, proporcionar uma nova forma de ensinar e aprender, através de uma educação que favoreça a formação de sujeitos críticos, autônomos e conscientes de seu papel na sociedade.

\subsection{Espaços e Possibilidades na Cibercultura}

Vivemos na sociedade contemporânea um novo momento tecnológico. A expansão das possibilidades de comunicação e de informação, por meio de equipamentos midiáticos, modifica nossa forma de viver, interagir e aprender na atualidade.

A sociedade está impregnada de tecnologias no seu âmago mais profundo, influenciando, diretamente, a rotina humana e a disposição das atividades dos homens. Devido a esta mudança ao longo dos últimos séculos, essas inovações demandam conhecimento por parte da sociedade que se torna a sociedade do conhecimento.

As TIC's são indispensáveis para a sociedade atual, suportando todos os ramos de atividade, possibilitando todo tipo de serviços, dos mais tradicionais aos mais inovadores, e criando condições para o fomento da atividade econômica em nível global. As novas tecnologias instaladas na sociedade e no trabalho levaram a profundas mudanças no campo social e individual, ao influenciarem, drasticamente, a vida humana, o tempo e o espaço. Elas fazem parte de nosso cotidiano, tão presentes que parecem ser algo natural. Sendo assim, Silva e Conceição (2013) destacam a ubiquidade relacionada à mobilidade das tecnologias móveis que permitem um contato estável a diversos lugares ao mesmo tempo. A possibilidade de nos comunicarmos com muitas pessoas ao mesmo tempo e em lugares diferentes faz com tenhamos a sensação de estarmos presentes naquele local.

Momento: diálogos em educação, E-ISSN 2316-3100, v. 28, n. 3, p. 390-409, set./dez, 2018. 
A aprendizagem no ciberespaço faz com que os ambientes de educação escolar se ampliem. Exige uma mudança de visão em relação às tecnologias nos novos tempos escolares, no modo de ensinar e de aprender, sendo um agregador de possibilidades didáticas em que o professor possa desenvolver projetos e atividades interessantes com seus alunos, tendo certa consciência de aproveitar e desenvolver o lado positivo da aprendizagem com as TIC's. Portanto, podemos perceber que o ciberespaço compõe uma nova forma de se comunicar, por meio da interligação de computadores em todo mundo, e a cibercultura enfatiza todas as ações que se instituem neste espaço. Nele, é possível a aproximação dos recursos disponíveis no computador, a troca de mensagens de forma síncrona ou assíncrona, a transmissão de vídeo e som, e, dentre outras, as possibilidades que aparecem diariamente.

É inevitável a importância das TIC's em todo contexto social, porém ainda vemos a escola demonstrar grande dificuldade em colocar na prática as transformações do modo de aprender em virtude do avanço tecnológico atual. A rápida difusão das TIC's exerce alterações em todas as áreas da sociedade contemporânea e assume importância central na vida social e individual na atualidade, consequentemente, os educadores e todos envolvidos no sistema da Educação devem estar motivados e preparados para enfrentar o futuro que se tem revelado incerto e em permanente mudança, para que todos possam contribuir da melhor forma com o sucesso educativo.

Ao longo do tempo, vem surgindo uma nova era que oferece múltiplas possibilidades de aprender, em que o espaço físico da escola, tão relevante em outras décadas, neste novo paradigma, deixa de ser o local exclusivo para a construção do conhecimento e da preparação do cidadão para a vida ativa. Nos dias de hoje, torna-se imprescindível formar alunos com espírito empreendedor, criativos e capacitados para resolver diversos problemas.

\subsection{O uso da tecnologia Facebook como ferramenta pedagógica}

As Tecnologias de Informação e Comunicação disponibilizam uma variedade de recursos para facilitar e enriquecer o ensino e a aprendizagem. As redes sociais representam grande capacidade de comunicação, conexão social e troca de informações.

Portanto, vivemos numa sociedade em que a informação se dá de forma cada vez mais rápida. Diante dessa realidade, as redes sociais são primordiais para o mundo atual, pois ferramentas como o Facebook possibilitam que acontecimentos sejam Momento: diálogos em educação, E-ISSN 2316-3100, v. 28, n. 3, p. 390-409, set./dez, 2018. 
visualizados quase que instantaneamente. Passam a utilizá-lo para reunir pessoas com causas semelhantes e objetivos comuns e fazer repercutir fatos, denúncias e outros.

O Facebook foi criado em 2004, em Harvard, nos Estados Unidos, por Mark Zuckerberg, logo se tornou a rede mais visitada no mundo. Segundo Martins (2015), a rede social Facebook possui atualmente 1.44 bilhão de usuários no mundo inteiro. Vem ganhando a preferência dos indivíduos que usam a Internet para a realização de várias tarefas, com compartilhamento de ideias e notícias, divulgação de acontecimentos e produtos que consideram interessantes.

Por meio de tecnologia 2.0, o Facebook possui um espaço convidativo para a partilha, a interação e o debate. Seu ambiente é informal, o indivíduo está à vontade para se comunicar. Encontra-se no endereço eletrônico www.facebook.com. Não é somente um canal de comunicação, mas uma ferramenta tecnológica para educação, pois se trata de uma plataforma conhecida, ou seja, popular, de fácil acesso e gratuita. Sua estrutura é vertical, formada por nós (ou nodos) que representam as pessoas e por ligações que são as relações de amizades que surgem a partir destes nós. Todos os seus membros são participantes ativos que visam não somente à colaboração, à partilha, à comunicação, mas, sim, ao crescimento pessoal. Sua comunicação pode ocorrer de forma assíncrona (comunicação não simultânea) ou síncrona (tempo real).

Os recursos e as possibilidades oferecidos pelo Facebook podem auxiliar na educação e na aprendizagem, através do contato entre as pessoas de diferentes níveis sociais, culturais, políticos, econômicos e educacionais. Os educadores podem tirar as dúvidas dos alunos de qualquer lugar e a qualquer hora, bem como promover atividades de grupo para proporcionar a interação entre os alunos e compartilhar conhecimentos e experiências.

As tecnologias web 2.0 - podcasts, wikis, redes sociais, dentre outras - estão presentes no dia a dia de nossos alunos. Portanto, surge uma nova função para os educadores em meio a estas mudanças tecnológicas que transformam a forma de agir e pensar da sociedade moderna - as quais provocam novas formas de ensinar e aprender, ou seja, exigem-se novas metodologias de ensino.

Um número considerável de pessoas usufrui das tecnologias, especialmente os jovens e os alunos. Nesse sentido, pode-se lançar o olhar para o potencial educativo da rede social Facebook, por meio de seus recursos e atividades que apoiam o ensino e a aprendizagem. . Os professores podem sanar as dúvidas dos alunos a qualquer hora e de qualquer lugar, proporcionar atividades em grupo, compartilhar conhecimentos e Momento: diálogos em educação, E-ISSN 2316-3100, v. 28, n. 3, p. 390-409, set./dez, 2018. 
experiências de forma colaborativa.

\section{METODOLOGIA}

O quadro epistemológico que ancorou esta investigação quanto à abordagem foi de natureza qualitativa. Ademais, caracterizou-se, fundamentalmente, por proporcionar ao investigador uma inter-relação com a realidade, desenvolvida de forma indutiva e sistemática. De acordo com seus objetivos, esta pesquisa é explicativa, já que se preocupa em apontar os fatores que determinam ou que cooperam para a ocorrência dos fenômenos. (Gil, 2009). Isso significa que este tipo de pesquisa explica o porquê das coisas, através dos resultados oferecidos. Gerhardt e Silveira (2009) referenciam (Gil 2007, p.43) para dizer que uma pesquisa explicativa pode seguir a trajetória de outra descritiva, embora a identificação dos objetos que determinam um fenômeno deva estar abundantemente descrito e detalhado. E, também, exploratória, segundo Gerhardt e Silveira (2009), a pesquisa exploratória tem como finalidade proporcionar maior intimidade com o problema, para torná-lo mais explícito ou para criar hipóteses.

Junto à investigação qualitativa, elencamos para este trabalho o Estudo de Caso, por considerarmos o mais adequado. O estudo de caso é uma abordagem metodológica que trata de um plano de investigação que envolve o estudo intensivo e detalhado de uma entidade bem definida: o caso.

Para estudar as questões elucidadas para a pesquisa, desenvolveu-se, na Educação Infantil, de uma escola pública do município de São Francisco de Paula, o projeto de intervenção "A ludicidade da matemática interagindo com a família através do Facebook" que envolveu 20 (vinte) crianças de 5-6 anos de idade e seus familiares. A finalidade é estimular a criança a ouvir e a refletir sobre a matemática, a partir de uma história infantil, bem como utilizar recursos tecnológicos, tais como o Facebook - para integrar a família e a escola em torno dos conteúdos escolares -, o qual foi utilizado como espaço para se comunicar, interagir e partilhar tarefas e atividades.

\section{ANÁLISE E DISCUSSÃO DOS DADOS}

Pela análise das entrevistas realizadas com os alunos e as famílias, em consonância com o projeto de intervenção e dialogando com alguns autores, surgiram as seguintes categorias: Televisão - Que tipo de tecnologia é mais usada em casa pelos pais e pelos filhos? Rádio, televisão, celular, jornal, revistas, computador? Os pais Momento: diálogos em educação, E-ISSN 2316-3100, v. 28, n. 3, p. 390-409, set./dez, 2018. 
consideram válida para comunicação essa tecnologia? Interação - Os pais conhecem o Facebook? Como os pais e irmãos mais velhos ou outras pessoas que moram na casa interagem com a tecnologia Facebook? Com que frequência usa a tecnologia Facebook? Acessibilidade - Para que utilizam? Postar fotos, vídeos? Curtir? Compartilhar? Falar com familiares e amigos? E os filhos? O que os pais pensam ou sabem que os filhos fazem no Facebook? Como os filhos usam o Facebook? Onde? Sozinhos? Com os irmãos? Com amigos? Com os pais? Para fazer o que? Planejamento prévio - E, para aprender, o Facebook será uma ferramenta tecnológica interessante? Os pais consideram que o Facebook pode ser usado pela escola, até mesmo para que a família fique sabendo o desenvolvimento escolar de seus filhos? Participação - Os pais conhecem o grupo fechado no Facebook: "Turminha Legal”? Por que não participam? Falta de tempo? Não tem Facebook? Não gostam?

A categoria "televisão" surgiu como a tecnologia mais usada em casa pela família, considerada válida para a comunicação.

FIGURA 1 - Tecnologia mais usada.

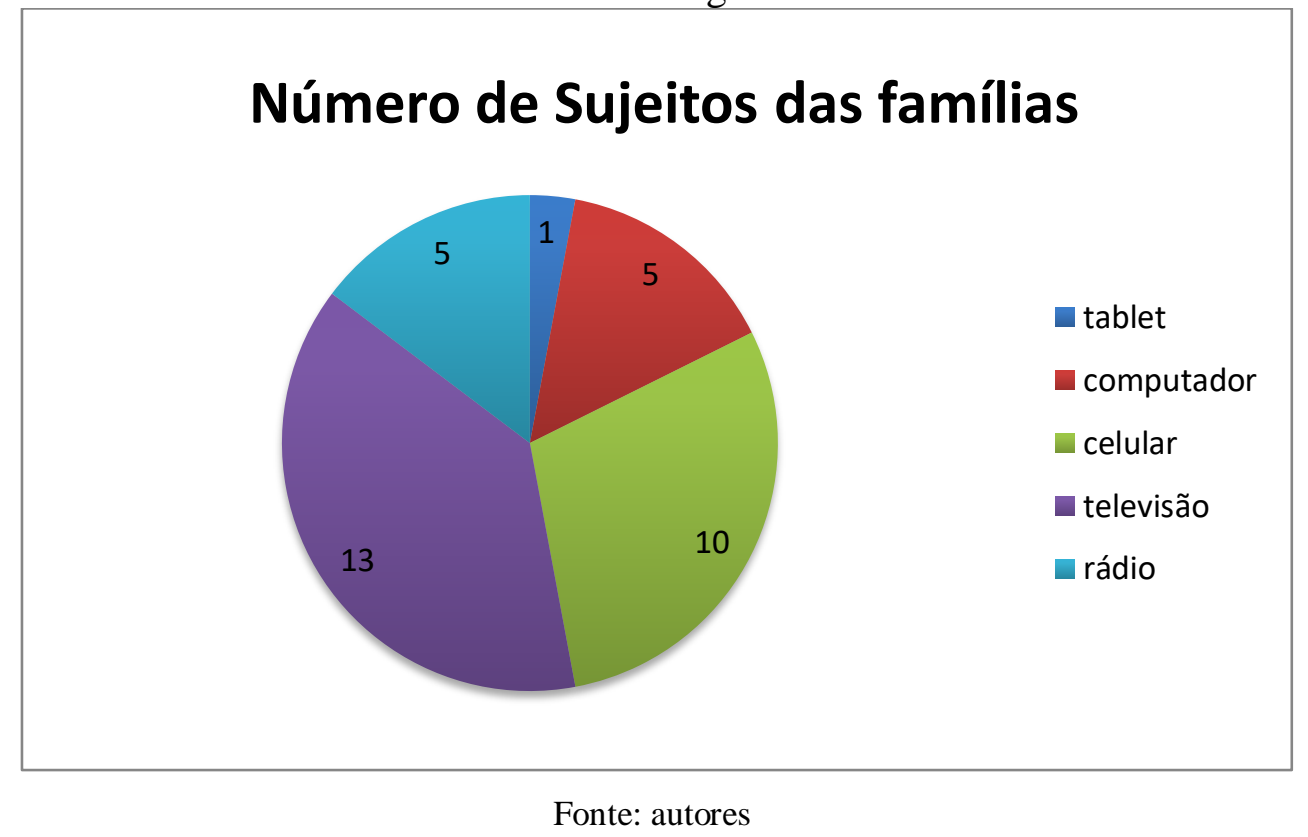

Durante a entrevista com os pais, percebeu-se que a televisão é a tecnologia mais usada pela família (13 sujeitos), seguida pelo celular (10 sujeitos). Alguns pais afirmaram ter mais de um aparelho de televisão em casa. Eles consideram a televisão como um meio de comunicação muito eficiente para saberem das coisas que acontecem no mundo, ou seja, as notícias, e, também, para entreterem-se. Como enfatiza Moutinho 
(2011), a televisão é ainda um meio de comunicação por excelência. Os alunos manifestaram o interesse no uso do celular para jogos, realização de gravações, armazenamento de fotos.

$\mathrm{Na}$ categoria "interação", percebeu-se, por meio das falas dos pais, que cada segmento da família interage, de alguma forma, com o Facebook.

O pai conhece, mas não faz uso. O mano usa principalmente para jogar. A mana utiliza para se comunicar com os amigos, falar com os colegas de faculdade, manter-se informada sobre os fatos do momento. A mãe usa para falar com amigos e parentes distantes, compartilhar assuntos interessantes e estudar. (o grupo da especialização possui um face privado onde estão alunos e professores, todos conversam, compartilham informações, tiram dúvidas. Os professores também mandam convites para eventos, exposições e outros).(Pai A)

O aluno A descreveu que olha sempre com o pai e que utiliza o Facebook para "conversar com as pessoas".

Segundo Ferreira, Corrêa e Torres, o Facebook é visto como um fenômeno mundial e estabelece uma nova forma de se relacionar.

Através da categoria “acessibilidade", notou-se que o Facebook é utilizado para desempenhar diferentes funções:

FIGURA 2 - Tipo de utilização do Facebook.

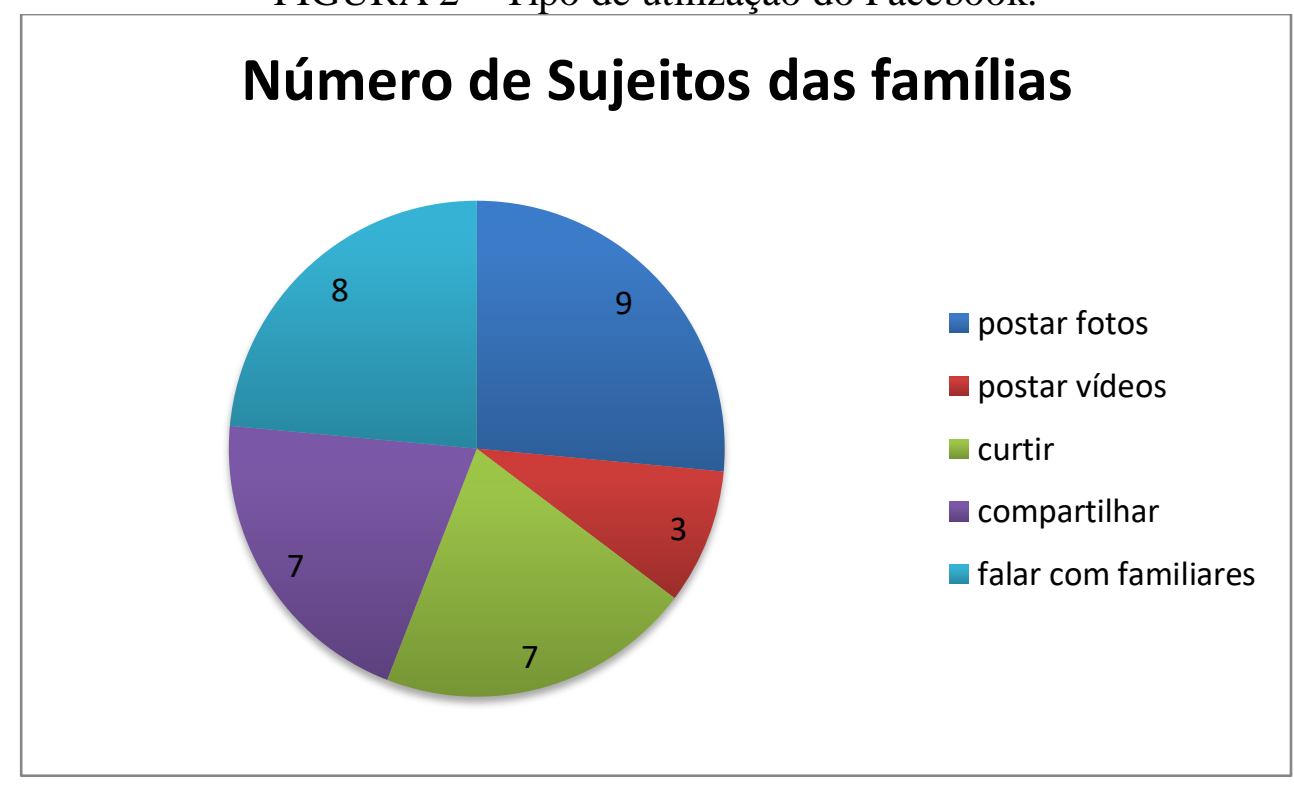

Fonte: autores

Segundo Jacobsen e Sperotto (2014), “As pessoas usam o Facebook para ficarem conectadas com amigos e familiares, para descobrir o que está acontecendo no 
mundo, e, para compartilhar e expressar o que importa para eles".

A categoria "planejamento prévio" surgiu a partir das questões: E, para aprender, o Facebook será uma ferramenta tecnológica interessante? Pode ser usado pela escola?

Acredito que sim, pois possuem páginas educativas. (Pai A)

Sim é importante, mas com a devida atenção do adulto responsável. (Pai B)

Eu acredito que sim. (Pai C)

Nas devidas proporções com certeza. (Pai F)

Ela é muito nova, mas mostramos as fotos que postamos para ela ver. (Pai G)

Depende. Primeiramente todos precisam ter acesso. É preciso ter um trabalho anterior que deve ser feito com os alunos, principalmente com os jovens, de que tem um objetivo para ser usado. Mas se todos compreenderem e tiverem acesso, penso que é uma ferramenta muito boa. (Pai J)

Por meio das falas dos familiares, constatou-se que o Facebook pode ser usado para aprendizagem, com as devidas precauções, ou seja, que haja um currículo adequado e um bom planejamento do professor.

A categoria "participação" está relacionada ao grupo do Facebook "Turminha Legal". Os pais foram questionados se conheciam o grupo, se participavam ou não dele.

Sim conheço. Eu participo. (Pai A)

Ainda não. Iremos participar, agora sabendo. (Pai B)

Sempre que posso eu mecho no grupo e curto tudo que postam. (Pai C)

Não temos face. (Pai D)

Ainda não conheço. Estou sem net no momento, mas vou pôr $e$ participar. (Pai E)

Não conheço. Falta tempo. (Pai F)

Sim. Falta tempo, mas assim que eu poder olho. (Pai G)

Não. Utilizamos muito pouco, apenas para o convívio social. (Pai $\mathrm{H})$

Não temos computador e nem internet e não gosto muito. (Pai J)

Conheço. Quando posso, participo. (Pai K)

Conheço e participo. (Pai L)

Segundo Amante e Faria (2014), é significativa a participação das famílias na vida escolar dos filhos, inclusive no que se refere à integração de recursos tecnológicos.

O não acesso à Internet ainda é um fator que faz com que as pessoas não consigam disponibilizar de recursos oferecidos nas redes sociais. Alguns pais relataram que não possuem Internet ou que, no momento, estão sem. Por isso, a dificuldade e a não participação no grupo da Turminha Legal. Por se tratarem de famílias oriundas de rendas mais baixas, segundo dados do PPP da Escola (2012), a Internet se torna um 
meio de consumo supérfluo em relação a outros meios considerados prioritários, tais como alimentação, água, luz, aluguel e vestuário.

Devido a pouca participação dos familiares no grupo, foi feito um novo chamamento através de um bilhete elaborado pela pesquisadora e também pelas conversas informais com alguns familiares que levam seus filhos à escola. Durante conversa informal com uma das mães, ela relatou que não tinha Facebook, porém eu poderia contatar sua filha, disponibilizando o endereço eletrônico.

Os pais limitaram-se, apenas, a curtir as postagens no grupo, no entanto, mesmo aqueles que não participavam do grupo, realizavam as atividades solicitadas junto às crianças, e as mesmas eram devolvidas para avaliação. Algumas dessas atividades foram postadas no grupo, bem como as atividades realizadas na sala de aula.

As atividades de matemática feitas pelas crianças na sala de aula ou no computador, com auxílio dos familiares em casa, demonstraram que as crianças possuem capacidade de resolver problemas pela troca de saberes com seus pares e na tomada de decisões.

De acordo com as falas dos pais e com a citação das autoras, considerou-se a participação da família no ambiente escolar fundamental para o desempenho das crianças, tanto no que se refere à aprendizagem quanto à construção das relações socioafetivas. Quando os pais se envolvem no processo educativo de seus filhos, estes se sentem mais seguros para tomarem decisões e apresentarem melhor desempenho nas atividades escolares.

\section{CONCLUSÃO}

Diante do que foi descrito sobre As TIC's na Educação Infantil: contribuições do Facebook para a aprendizagem e para a integração família e escola, pode-se dizer que ainda são muitos os desafios para a inserção das tecnologias de informação e de comunicação na escola.

O tema escolhido foi de grande importância, pois despertou um interesse maior por parte dos alunos e familiares em relação à questão das novas tecnologias como recurso pedagógico para aprendizagem das crianças. Percebeu-se que as TIC's são ferramentas que possibilitam a aprendizagem das crianças de forma mais significativa e prazerosa, favorecendo a praticidade das aulas e aprendizagens, despertando a curiosidade e a criatividade das crianças da educação infantil.

Momento: diálogos em educação, E-ISSN 2316-3100, v. 28, n. 3, p. 390-409, set./dez, 2018. 
Lançando olhar para a análise das entrevistas, postagens e realização das tarefas no grupo do Facebook, podemos perceber que existe. por parte dos pais. um interesse nas atividades desenvolvidas na escola. Cabe ressaltar que a rede social Facebook possibilitou uma ligação entre escola-família em torno dos conteúdos educativos. Apesar de não autorizarem a compartilhar, comentar ou, até mesmo, postar as atividades no grupo, limitam-se, apenas, a curtir o que era postado. porém as tarefas de casa eram realizadas e devolvidas à escola. Considerou-se muito significativo este movimento, pois, de uma forma ou de outra, os pais estavam participando, mesmo aqueles que não faziam parte do grupo.

A utilização da rede social Facebook empreendeu um espaço com um percurso que não pode ser esquecido ou computado a este estudo.

\section{REFERÊNCIAS}

ALMEIDA, M. E. B. (2008). Educação e tecnologias no Brasil e em Portugal em três momentos de sua história. In: Educação, Formação e Tecnologias, PP 23-36. Disponível em http://eft.educom.pt

AMANTE, Lúcia \& FARIA, Adila. Escola e tecnologia digitais na infância. In: P. L. Torres (org.). Complexidade: redes e conexões na produção do conhecimento. Curitiba: Coleção Agrinho, pp 412. 2014.

Belloni, M. L.. Educação à distância. Campinas: Autores Associados, 2009.

BRASIL, Ministério da Educação. Referencial Curricular Nacional para Educação Infantil. v. 3, Brasília. 1998.

FERREIRA, Jaques de Lima.; CÔRREA, Barbara Raquel \& TORRES, Patrícia Lupion. O uso pedagógico da rede social facebook. In: Redes Sociais e Educação: desafios contemporâneos. (n.d.).

FERREIRA, P. M. P. G. Quadros Interactivos: novas ferramentas, novas pedagogias, novas aprendizagens. Dissertação (Mestrado) - Instiututo de Educação, Universidade do Minho, 2009.

GERHARD, Tatiana Engel \& SILVEIRA, Denise Tolfo. Métodos de pesquisa. EAD série educação a distância. Porto Alegre: UFRGS. 120p. 2009.

GIL, Antônio Carlos. Como elaborar projetos de pesquisa. São Paulo: Atlas S. A. 2009. JACOBSEN, Daniela Renata \& SPEROTTO, Rossária Ilgenfritz. O facebook como um ambiente de aprendizagem colaborativa para o ensino da matemática. Aprendizagem Online: III Congresso Internacional TIC e Educação. (p. 1500). Lisboa: TicEDUCA. 2014. 
LEITE, W. S. \& DO RIBEIRO, C.A. N. (2012). A Inclusão das TICs na Educação Brasileira: Problemas e Desafios. Magis, Revista Internacional de Investigación em Educación, 173-187. Recuperado em: http://www.redalyc.org/articulo.oa?id=281024896010

MARTINS, Laura. Facebook revela total de usuários de whatsApp, instagran, vídeos e mais. 2015. Disponível em: http://www.techtudo.com.br/listas/noticia/2015/04/facebook-revela-total-de-usuariosde-whatsapp-instagram-videos-e-mais.html. Acesso em: 26 set. 2015.

MEIRINHOS, Manuel \& OSÓRIO, António. A colaboração em ambientes virtuais: aprender e formar no século XXI. Braga: Associação ArcaComum. 2014.

Moran, J. M. (2007). A educação que desejamos: novos desafios e como chegar lá. Campinas: Papirus, 2007

MOUTINHO, Tiago da Conceição. SIC K no facebook: dinamização e participação das crianças. Dissertação (Mestrado em Comunicação e Multimédia), Agregação do Departamento de Comunicação e Arte, Universidade de Avero. 2011. Disponível em: http://biblioteca.unifacef.com.br/link/?id=487292. Acesso em: 12 jun. 2015.

OLIVEIRA, E. S.; SALGADO, R. G. \& NALLI, L. Informática e redes sociais: o que dizem as crianças sobre a fama e o facebook em contextos educativos? Challenges 2015: meio século de TIC na educação. p. 63-76, 2015

PESCE, L.. EAD - antes e depois da cibercultura. In: Cibercultura: o que muda na educação (p. 32). TV Escola/Salto para o Futuro, 2011.

RODRIGUES, Herik Zednik; TAROUCO, Liane Rochenbach \& KLERING, Luis Roque Incorporação das TIC à gestão escolar e a prática pedagógica: indicadores para o desenvolvimento da e-Maturity. In: M. B. G. Silva \& M. L. R. Flores, Formação a distância para gestores da educação básica: olhares sobre uma experiência no Rio Grande do Sul (p. 400). Porto Alegre: Evangraf. 2014.

SILVA, Bento. A tecnologia é uma estratégia. In: P. Dias \& C. V. Freitas. Actas da II Conferência Internacional Desafios. Braga: Centro de Competência da Universidade do Minho do Projecto Nónio, pp. 839-859. 2001.

SILVA, Bento \& CONCEIÇÃO, Silva Carla. Desafios do b-learning em tempos de cibercultura. In: M. B. Almeida; P. Dias \& B. D. Silva, Cenários de inovação para a educação na sociedade digital (p. 187). Braga: Loyola. 2013.

SILVA, Marco. (org.). Formação de professores para a docência online. São Paulo: Loyola. 2012. Disponível em: http://sistemas3.sead.ufscar.br/ojs/Apresentação SIED EnPED Marco\%20silva.pdf.

Acesso em: 18 dez. 2013.

VALENTE, J. A. (org.). O computador na sociedade do conhecimento. Campinas: UNICAMP/NIED, 1999. 